\title{
Indeterminate NPIs and Scope
}

\author{
Junko Shimoyama \\ McGill University
}

\section{Indeterminate NPIs}

It is widely accepted that English negative polarity item (NPI) any is interpreted as a narrow scope existential with respect to its licensor, rather than as a wide scope universal (Ladusaw 1979, Carlson 1980). In the literature on Japanese NPIs, it has been a common assumption that the narrow scope existential analysis of English any will naturally carry over to its Japanese counterpart in the form of indeterminate pronoun + mo (e.g., Nam 1994, Kawashima 1994).

This common assumption, however, presents a puzzle when considered with a more general picture of how quantification is expressed in Japanese, as also noted by Hagstrom (1997). As shown in (1), the quantificational force of the socalled indeterminate pronouns is determined depending on which particle they occur with. For instance, we can see that $k a$ contributes the existential force in (1b), and mo contributes the universal force in (1c).

(1) A partial list of indeterminate pronouns

dare (person) nani (thing)

a. da're...Q 'who'

b. da're-ka 'someone'

c. da're-mo 'everyone' * na'ni-mo 'everything'

d. dare-mo 'anyone ${ }_{\mathrm{NPI}}$ '

e. dare-de-mo 'anyone ${ }_{\mathrm{FC}}$ '
na'ni...Q 'what'

na'ni-ka 'something'

nani-mo 'anything $\mathrm{NPI}_{\text {' }}$

nan-de-mo 'anything ${ }_{\mathrm{FC}}$ ' doko (place)

do'ko...Q 'where'

do'ko-ka 'somewhere'

do'ko-mo 'everywhere'

doko-mo 'anywhere $\mathrm{NPI}$

doko-de-mo'anywhere $\mathrm{FC}$ '

Note that the universal series in (1c) and the NPI series in (1d) differ only in accentual patterns: the former is accented, while the latter is unaccented. ${ }^{1}$

I wish to thank audiences at SALT 18 and WCCFL 27 for useful comments, in particular, Gennaro Chierchia and Anna Szabolcsi. I am also grateful to Bernhard Schwarz and Arnim von Stechow for comments and discussions on earlier versions, and to Tomohide Kinuhata for bringing Kataoka (2006a) to my attention. Preliminary versions of the paper were presented in 2003 at the University of Texas at Austin and at the Symposium on the Indeterminate: WH and Indefinite Noun Phrases at the 21st Annual Meeting of the English Linguistic Society of Japan in Shizuoka, and in 2004 at the University of Tokyo and GURT 2004. I am most grateful to those who provided me with judgments - Hitoshi Horiuchi, Makiko Irie, Makoto Kanazawa, Takeo Kurafuji, Kiyomi Kusumoto, and SALT reviewers. The work reported here was supported in part by a grant from FQRSC, Établissement de nouveaux professeurs-chercheurs 213154, which I gratefully acknowledge.

${ }^{1}$ This morphological fact is only suggestive, and is not by itself a strong argument for assuming that the particle -mo always contributes universal force. For example, the same particle also shows up in minimizers such as it-teki-mo (one- $\left.\mathrm{CL}_{\mathrm{drop}}-\mathrm{MO}\right)$ 'even a single drop' and hito-kakeramo (one- $\mathrm{CL}_{\text {piece }}-\mathrm{MO}$ ) 'even a single piece'. 
Relative syntactic relations between sentential negation and indeterminate NPIs (or any arguments or adjuncts) are not straightforwardly observable in Japanese. This is due to factors such as the strictly head final and agglutinative nature of the language and the availability of scrambling (see Han et al. 2007, for example). Sentential negation is known to take relatively low scope in general, and this may fit with the idea that the indeterminate NPIs are wide scope universals. However, the narrow scope tendency of sentential negation does not by itself provide a solid basis for analyzing indeterminate NPIs as universals. It is possible that negation takes wide scope over arguments as shown in (2).

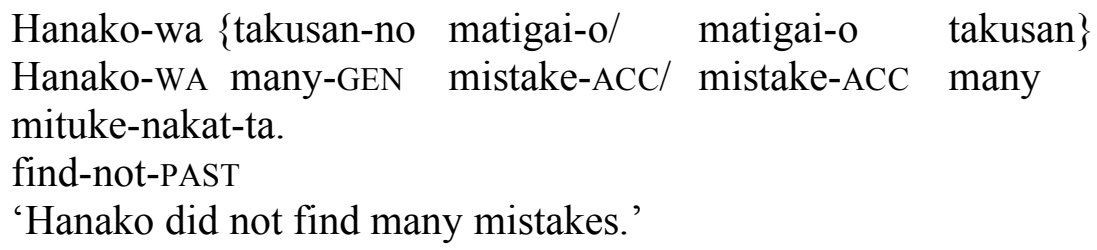

This paper is a first attempt to scrutinize the common assumption that the indeterminate NPIs are narrow scope existentials. In most contexts, the indetermiante NPIs can be analyzed as either existential or universal. In fact, as will be explained shortly, properties of the indeterminate NPIs and certain other properties of the grammar of Japanese conspire to make it very difficult to tease apart these two analyses. A significant finding of the paper is that there are instances of indeterminate NPIs in certain contexts that can only be analyzed as wide scope universals.

This result is particularly interesting in view of the recent conclusions independently reached in Sells (2006) and Kim and Sells (2007) that some NPIs in Korean are universals. If we are on the right track, the paper adds another instance to the category of polarity sensitive universal expressions that need to undergo QR to right above negation, as argued for in Giannakidou (2000). ${ }^{2,3}$

The licensing requirement for these polarity sensitive universal expressions is that they sit outside the scope of negation. What this means is that these expressions fall outside of the scope of a recent body of work that attempts to provide an answer to the question as to why any-type NPIs have the distribution they have (e.g, Kadmon and Landman 1993, Lahiri 1998 and Chierchia 2004). This is not a drawback, as far as indeterminate NPIs in Japanese (and Korean) are concerned. Even though the fact that mo means 'also' or 'even' when it associates with non-indeterminate phrases may invite an analysis analogous to Lahiri's (1998) analysis of NPIs in Hindi, this would not work because the distribution of indeterminate NPIs is far more limited than that of Hindi NPIs, as we will see in the next section. The Lahiri-style analysis would overgenerate.

\footnotetext{
${ }^{2}$ See also Szabolcsi (1981), in which n-words in Hungarian are proposed to be universal quantifiers that outscope negation.

${ }^{3}$ In this paper I leave it open whether it is the sentential negation itself, possibly having undergone head movement, or the abstract negation that is interpreted (Penka and von Stechow 2001, Zeijlstra 2004).
} 
Some notes are in order. The view that expressions requiring the presence of negation or other licensers are in the scope of these licensers is so prevalent in the literature that the term NPI is sometimes used in a narrower sense, excluding those items that need to outscope their licensers. I do not adopt this narrow sense of the term here. Also, the question this paper addresses is independent of the question of whether indeterminate NPIs should be viewed as negative concord items, and if so, whether they are negative quantifiers or not (Penka and von Stechow 2001, Watanabe 2004, Zeijlstra 2004). ${ }^{4}$

\section{Anti-additivity: The Difficulty in Distinguishing the Two Competing Analyses}

The licensing environment for the indeterminate NPIs is much more limited than English NPI any. The indeterminate NPIs are licensed by sentential negation as shown in (3), but are not licensed in other contexts where any is licensed, as shown in (4). ${ }^{5}$ In this sense, they are like English one bit and Korean amwu-to 'anyone', for example (Nam 1994).

Yoko-ga gakusei-o dare-mo $\quad\left\{{ }^{*}\right.$ syootaisi-ta/syootaisi-nakat-ta $\}$. Yoko-NOM student-ACC who-MO invite-PAST/invite-not-PAST

'Yoko $\{*$ invited any student/didn't invite any student $\}$.'
a. *[[Nani-mo yon-da] dono gakusei-mo] gookakushi-ta. what-MO read-PAST which student-MO pass-PAST
'Every student who read anything passed.'
b. *[Go-nin ika-no gakusei]-ga nani-mo yon-da. five-CL $L_{\text {person }}$ fewer.than-GEN student-NOM what-MO read-PAST.
'Fewer than five students read anything.'

Furthermore, just having sentential negation somewhere in the sentence is not enough for licensing indeterminate NPIs, as shown in (5). They need to be licensed by clausemate negation (Muraki 1978, Kato 1985).
*Taro-wa [Yoko-ga dare-mo syootaisi-ta
to] iwa-nakat-ta.
Taro-TOP Yoko-NOM who-MO invite-PAST
that say-not-PAST
'Taro didn't say that Yoko invited anyone.'

Given that the indeterminate NPIs are licensed solely by local sentential negation, a difficulty arises in distinguishing the predictions made by the narrow scope existential analysis and the wide scope universal analysis. Sentential

\footnotetext{
${ }^{4}$ Data to be presented in Section 3.2, where negation and indeterminate NPIs do not take adjacent scope, suggest that they are at least not simple negative quantifiers as proposed in Watanabe (2004).

${ }^{5}$ Indeterminate NPIs are also licensed in the context of nasi-de 'without', where nasi is related to the sentential negation morpheme $n a(k)$.
} 
negation denotes a function that validates the equivalences in (6). These are the functions that are called anti-morphic functions in Zwarts (1998).

$$
\begin{array}{ll}
\text { a. } & \mathrm{f}(\mathrm{A} \vee \mathrm{B})=\mathrm{f}(\mathrm{A}) \wedge \mathrm{f}(\mathrm{B}) \\
\text { b. } & \mathrm{f}(\mathrm{A}) \vee \mathrm{f}(\mathrm{B})=\mathrm{f}(\mathrm{A} \wedge \mathrm{B})
\end{array}
$$

Of particular relevance here is (6a), which by itself characterizes what is called anti-additive functions (Zwarts 1998). It says that narrow scope disjunction with respect to function $\mathrm{f}$ is equivalent to wide scope conjunction with respect to $\mathrm{f}$. In the context of indeterminate NPIs, this amounts to saying that narrow scope existential with respect to negation is equivalent to wide scope universal with respect to negation (i.e., one of De Morgan's laws). Thus, as long as we look at simple data, it seems almost impossible to tell whether these NPIs are existential or universal.

Thus, on the one hand, we want to look at contexts in which licensing expressions do not denote anti-additive functions. On the other hand, we cannot just take any non-anti-additive expressions since indeterminate-mo NPIs require sentential negation, which is anti-morphic, hence necessarily anti-additive. In the next section, we circumvent this difficulty by looking at slightly more complex cases.

\section{Constructing Decisive Cases}

\subsection{Non-anti-additive Contexts}

In the next subsection, I present cases where indeterminate NPIs are interpreted as wide scope universals, but not as narrow scope existentials. I do so by constructing cases in which an additional quantificational element in conjunction with sentential negation creates a non-anti-additive context. If a quantificational element $\mathrm{Q}$ and sentential negation $\neg$ in combination is a non-anti-additive function $\mathrm{Q} \neg$, i.e., a function that does not validate the equivalence in (6a), we should be able to tell whether an indeterminate NPI is interpreted as existential in the scope of $\mathrm{Q} \neg$, or as universal taking scope over $\mathrm{Q} \neg$, because of the nonequivalence of $\mathrm{Q} \neg \exists$ and $\forall \mathrm{Q} \neg$. Likewise, a non-anti-additive function $\neg \mathrm{Q}$ would create a telling context because of the non-equivalence of $\neg \mathrm{Q} \exists$ and $\forall \neg$ Q. Some examples of non-anti-additive expressions of the form $\mathrm{Q} \neg$ are mostly not, rarely, many not, more than $n$ not. Examples of non-anti-additive expressions of the form $\neg \mathrm{Q}$ include not mostly, not always, not many, not more than $n$.

For illustration, let us briefly look at example (7) from Ladusaw (1979), which is presented as one of the arguments for the narrow scope existential analysis of any.

(7) The IRS rarely audits anyone. 
The scope predicted by the existential anlaysis is rarely $>$ anyone $_{\exists}$, whereas the scope predicted by the universal analysis is anyone ${ }_{\forall}>$ rarely. Since rarely (analyzed as usually + not in Ladusaw 1979) is non-anti-additive, these two scope relations do not end up equivalent. The reading predicted by the existential analysis is (8a), while the reading predicted by the universal analysis is $(8 b)$.

a. It is usually not the case that there is someone whom the IRS audits. (= The IRS almost always audits no one.)

b. *Everyone is such that it is usually the case that the IRS doesn't audit him.

Since reading (8b) is not available, Ladusaw (1979) concludes that any must be an existential (see also Gajewski 2008). ${ }^{6}$ The argument I will present in this paper is similar in structure to the rarely case above, but it points toward the opposite conclusion that we must recognize cases of indeterminate NPIs that are interpreted as universals.

Going back to our own experiment in Japanese, in a sentence that contains a non-anti-additive function of the form $\mathrm{Q} \neg$, the existence of the reading in (9b) is evidence that the indeterminate NPI is interpreted as wide scope universal. This is because, if it was existential, it would have to be interpreted in the scope of negation as in (9a), and that is not equivalent to (9b). In contrast, the existence of the reading in (9a) is not telling because it is equivalent to (9a').

$$
\begin{array}{ll}
\text { a. } \quad \mathrm{Q} \neg>\exists & =\mathrm{a}^{\prime} . \quad \mathrm{Q} \forall \neg \\
\text { b. } \forall>\mathrm{Q}\urcorner & \\
\text { a. } \quad \neg \mathrm{Q}>\exists & \\
\text { b. } \forall>\neg \mathrm{Q} & =\text { b'. } \neg \exists \mathrm{Q}
\end{array}
$$

A similar story carries over to the configurations in (10) using a non-anti-additive function of the form $\neg \mathrm{Q}$. If a sentence has a reading that corresponds to (10a), that is evidence for the existential interpretation of the indeterminate NPI, because this reading is not paraphrasable in the universal analysis. The existence of the reading in $(10 \mathrm{~b})$, on the other hand, is not informative for our purposes because it is equivalent to (10b').

The acute reader will have noticed that there is a potential problem in this experimental design. The telling configurations $(9 \mathrm{~b})$ and (10a) violate a familiar constraint known as the immediate scope constraint (Linebarger 1987, Guerzoni 2006) or a generalized version of it below (Kim and Sells 2007: 88).

(11) An NPI and negation are in an immediate scope relation with each other.

\footnotetext{
${ }^{6}$ The assumption here is that rarely is not syntactically decomposed so as to allow anyone to occur between usually and not. If that was a possibility, the existential and universal analyses cannot be teased apart. This issue is not relevant to the Japanese examples to follow.
} 
The absence of the reading in (9b) or (10a) therefore does not necessarily constitute direct evidence against the universal analysis or the existential analysis, respectively, as it can be attributed to this constraint.

As an illustration, consider the sentence in (12).

Dare-mo ooku-no seizika-o yoba-nakat-ta. who-MO many-GEN politician-ACC invite-not-PAST 'No one invited many politicians.'

If the reading in (9b) $\left.\forall>\mathrm{Q}_{\operatorname{many}}\right\urcorner$, paraphrased in (13), was available, that would be evidence for the universal interpretation of the subject dare-mo 'who-mo', as the reading is not equivalent to $(9 a) Q_{\text {many }} \neg>\exists$.

(13) For everyone, there are many politicians that he or she did not invite. $(\forall$ Qmany $\neg)$

The reading, however, is not available. ${ }^{7}$ But we cannot conclude from this that dare-mo 'who-mo' cannot be interpreted universally, as the unavailability of the reading may well be due to the generalized immediate scope constraint. The only reading available for the sentence is (10b) $\forall>\neg Q_{\text {many }}$, paraphrased in (14a). This is not telling, as we saw above, because of its equivalence to $\neg \exists Q_{\text {many }}$ in (14b).

a. For everyone, it is not the case that he or she invited many politicians.

b. It is not the case that someone invited many politicians. $\quad \neg \exists \mathrm{Q}_{\text {many }}$

Similarly, the lack of the reading in (10a) $\neg Q_{\text {all }}>\exists$ in sentence (15) does not directly suggest that indeterminate NPIs cannot be existentials, because zen 'in 'all' intervenes between negation and the NPI. ${ }^{8}$ The absent reading can be expressed by the bi-clausal sentence in (16).

$\begin{array}{clll}\text { ?*Zen'in-wa } & \text { omiyage-o } & \text { nani-mo } & \text { motteko-nakat-ta. } \\ \text { all-wA } & \text { souvenir-ACC } & \text { what-MO } & \text { bring-not-PAST }\end{array}$

Intended: 'It is not the case that everyone brought some or other souvenir.'

\footnotetext{
${ }^{7}$ The reading in (9a) $\mathrm{Q}_{\text {many }} \neg>\exists\left(=\mathrm{Q}_{\text {many }} \forall \neg\right)$ is not available either presumably due to the LF scope relation between ooku-no seizika 'many politicians' and the NPI that does not respect their surface scope relation. The reading in (10a) $\neg Q_{\text {many }}>\exists$ is also unavailable for the same reason, as well as due to the violation of the immediate scope constraint.

${ }^{8}$ The non-anti-additive function of the form $\neg \mathrm{Q}$ is created here by forcing zen' in 'all' take scope under negation by the use of -wa. Note that without the NPI, the sentence is fine, as shown in (i).

(i) Zen'in-wa omiyage-o motteko-nakat-ta.

all-WA souvenir-ACC bring-not-PAST

'Not all brought a souvenir.'
} 
[Zen'in-ga omiyage-o nani-ka motteki-ta]-wake-de-wa nai. all-NOM souvenir-ACC what-KA bring-PAST-WAKE-COP-WA not 'It is not the case that everyone brought some or other souvenir.'

\subsection{Universal Indeterminate NPIs}

With this much background in mind, let us move on to crucial data. Recall from above that in a sentence that contains a non-anti-additive function of the form $\mathrm{Q} \neg$, the existence of the reading in (9b) $\forall>\mathrm{Q} \neg$ is evidence that the indeterminate NPI is interpreted as wide scope universal. If a sentence with a non-anti-additive function of the form $\neg \mathrm{Q}$ has a reading that corresponds to (10a) $\neg \mathrm{Q}>\exists$, that is evidence for the existential interpretation of the indeterminate NPI.

Despite the fact that the configuration in (9b) $\forall>\mathrm{Q} \neg$ violates the generalized immediate scope constraint, we find cases where the constraint is lifted, making this reading possible. These cases involve quantificational adverbs which create non-anti-additive environment together with sentential negation. ${ }^{9}$

Two adverbs are used in examples (17) and (18), hudan-wa 'usually-wA' and taitei 'mostly', that must be interpreted outside the scope of negation generally. This ensures a non-anti-additive context created by $\left.\mathrm{Q}_{\mathrm{adv}}\right\urcorner$ as in (9). Strikingly, the reading in (9b) $\left.\forall>\mathrm{Q}_{\mathrm{adv}}\right\urcorner$ is indeed possible in these sentences, showing that these NPIs are interpreted as universal.

Nihonzin gakusei-no dare-mo hudan-wa sankasi-nakat-ta. Japanese student-GEN who-MO usually-WA participate-not-PAST 'For every Japanese student, it was usually the case that he or she did not participate.'

(18) Kokyaku-no dare-kara-mo gozentyuu-wa taitei denwa-ga nakat-ta. client-GEN who-from-MO morning-WA mostly call-NOM not.exist-PAST 'For every client, it was mostly the case that there was no call from him or her in the mornings.'

Note that the reading in (9a) is possible in addition, but a pause after the NPI makes the crucial reading in (9b) more readily available. This is presumably because this prosodic pattern makes the inverse or reconstructed scope reading inaccessible. $^{10}$

\footnotetext{
${ }^{9}$ Itumo or tuneni 'always' interpreted above negation, for instance, cannot be used in our experiment as they create an anti-additive context.

${ }^{10}$ I would like to thank a SALT reviewer for pointing out to me the connection between the reading in question and this particular type of prosody involving a pause after the NPI. Further investigation of this connection is left for future research. The reviewer also points out that in the following example, if there is a pause after dare-mo, the only reading available is the one with the scope relation $\left.\forall>Q_{\text {three }}\right\urcorner$. If this judgment can be replicated generally, the data would supplement the observation made in this section, which is only based on data with quantificational adverbs.

(i) Dare-mo wain-o san-syurui nom-anakat-ta.

who-MO wine-ACC three-kind drink-not-PAST

'For everyone, there are three kinds of wine that he or she didn't drink.' $\quad \forall>\mathrm{Q}_{\text {three}}$ ?
} 
More examples of the similar kind are provided below from Shimoyama (2004). The translations given below are only for the crucial reading in (9b) $\forall>$ $\left.\mathrm{Q}_{\mathrm{adv}}\right\urcorner$. The reading in which $\mathrm{Q}_{\mathrm{adv}}$ takes the widest scope may also be available, especially when a pause is not placed between the NPI and the quantificational adverb. This reading, however, is not relevant for our purposes, as it does not tease apart the universal and existential analyses of the indeterminate NPIs. The continuations in parentheses in (19) and (20) are intended to make the relevant readings easier to obtain. ${ }^{11}$
Dare-mo hudan-wa
kopiisitu-ni-wa i-nai yo.
who-MO usually-wA
copy.room-in-WA is-not PRT
(Iru-to sureba, zibun-no
happyoo-no
mae-dake-da.)
is if self-GEN presentation-GEN before-only-COP.NONPAST
'For everyone, it is usually the case that he or she is not in the copy room.
(For each person, if he or she is ever there, it's only before his or her presentation.)'

Itoko-no dare-kara-mo taitei-no baai nengazyoo-ga ko-nai. cousin-GEN who-from-MO most-GEN case new.year's.card-NOM come-not (Kuru-to sureba, kekkonsi-ta tosi-dake-da.)

come if marry-PAST year-only-COP.NONPAST

'For every cousin of mine, it is mostly the case that a new year's card does not come from him or her. (For each cousin, if one comes from him or her at all, it's only in the year when he or she got married.)'
Dare-mo mettani
kono takarakuzi-ni-wa atara-nakat-ta.
who-MO in.almost.all.cases this lottery-DAT-WA win-not-PAST
'For everyone, it was almost always the case that he or she didn't win this (type of) lottery.'

Naturally, the judgments involved are not the most straightforward, as they require computing of three scope bearing elements. Some speakers find it easier to get the relevant reading with some examples than the others, which may be related to the choice of quantificational adverbs used. Yet, it is encouraging that the judgments I have collected point toward the same direction, suggesting that the availability of the universal interpretation of the indeterminate NPIs needs to be recognized. ${ }^{12}$

\footnotetext{
${ }^{11}$ Mettani in (21) is an adverbial NPI which, together with clausemate negation, can be paraphrased as 'rarely'. Given its original meaning, it seems reasonable to assume that mettani by itself means something like 'almost always' or 'in many cases', scoping above negation.

${ }^{12}$ Nani-mo 'what-MO', as opposed to dore-mo 'which-MO', seems special in that it is nondistributive. It does not sound good in the type of configurations that are used in this section.
} 


\subsection{Existential Indeterminate NPIs?}

Consider now the examples in (22) and (23). The adverbs hinpanni-wa 'oftenWA' and tuneni-wa 'always-WA' are necessarily interpreted in the scope of negation, thus creating a non-anti-additive context with $\neg \mathrm{Q}_{\mathrm{adv}}$. In contrast to the examples in the last subsection, examples (22) and (23) lack the (a)-readings, which should, in principle, be available if the configuration (10a) $\neg \mathrm{Q}_{\mathrm{adv}}>\exists$ was. The absent (a)-reading of (22), for example, can be expressed by example (24). The (b)-readings are possible, where, interestingly, the quantificational adverb and the NPI do not maintain the surface scope relation.

Taro-wa hinpanni-wa doko-e-mo dekake-nakat-ta.

Taro-WA often-wA where-to-MO go.out-not-PAST

a. *'It is not the case that often, Taro went out to some place or other.'

b. 'There was no place that Taro went out to often.'

Sono uketuke-ni-wa tuneni-wa dare-mo i-nakat-ta.

that reception-at-WA always-WA who-MO exist-not-PAST

a. *'It's not the case that always, there was someone or other at the reception.'

b. 'There was nobody who was always at the reception.'

Taro-wa hinpanni doko-ka-e dekake-ta wake-de-wa nai. Taro-WA often where-KA-to go.out-PAST WAKE-COP-WA not

a. 'It is not the case that often, Taro went out to some place or other.'

b. 'It is not the case that there was some place that Taro went out to often.'

As I mentioned in Section 3.1, the lack of this reading does not provide direct evidence against the existential analysis. It may well be due to the violation of the immediate scope constraint. It remains to be seen whether there are cases where indeterminate NPIs can only be interpreted as existentials. For the crucial configuration (10a) $\neg \mathrm{Q}>\exists$ to be observable, one must find a quantificational element that is interpreted under negation but does not give rise to the violation of the immediate scope constraint.

We have seen that the availability of the universal interpretation of the indeterminate NPIs needs to be recognized, but we have not found crucial evidence for the existential interpretation of the indeterminate NPIs. Though, strictly speaking, the existential analysis has not been excluded yet, I will adopt a simpler hypothesis at this point that the indeterminate NPIs are universals, rather than the hypothesis that they are ambiguous. In the next section, I provide further support for the universal analysis of indeterminate NPIs. 


\section{Additional Support: Conflicting Requirements}

In this section, I look at the following type of configurations, similar to those in the previous section. $\mathrm{XP}_{\text {narrow }}$ represents phrases that need to be interpreted inside the scope of negation, while $\mathrm{XP}_{\text {wide }}$ represents those that need to be interpreted outside the scope of negation.
a. ᄀ
$\mathrm{XP}_{\text {narrow }}$ ind-NPI
b. ind-NPI
$\mathrm{XP}_{\text {wide }} \quad \neg$

Given that surface scope relations must be preserved at LF in general, if XP is interpreted under negation as in (25a), the NPI must be, too, and if XP is interpreted above negation as in (25b), the NPI must be, too. Then, the narrow scope existential analysis of indeterminate NPIs predicts that (25a) is acceptable and $(25 \mathrm{~b})$ is not, while the wide scope universal analysis predicts the opposite. As before, however, one needs to keep in mind that both (25a) and (25b) could incur violation of the generalized immediate scope constraint.

\subsection{Indeterminate NPIs and Minimizer NPIs}

First, we examine configuration (25a), using minimizer NPIs of the form 'oneclassifier-even' such as it-teki-mo 'one-CLdrop-even' and hito-tubu-mo 'one-CLgraineven'. The examples from (27) to (29) are modeled after Korean examples such as (26) in Sells (2006). I assume that at least the one-part of a minimizer NPI is reasonably analyzed as being in the scope of negation (see e.g., Lahiri 1998, Nakanishi 2006). ${ }^{13}$

a. Amwu-to han phwun-to nay-ci anh-ass-ta. anyone one cent-even give-COMP NEG-PAST-DECL

'Noone gave even one cent.'

b. ??Han salam-to amwu kes-to nay-ci anh-ass-ta. one person-even anything give-COMP NEG-PAST-DECL 'Not one person gave anything.'
a. Dare-mo it-teki-mo kobos-anakat-ta. who-MO one-CL $\mathrm{C}_{\mathrm{drop}}$-even spill-not-PAST
'Noone spilled even a single drop.'
b. ??Hito-ri-mo dore-mo tabe-nakat-ta. ${ }^{14}$ one- $\mathrm{CL}_{\text {person-even }}$ which-MO eat-not-PAST 'Not a single person ate anything.'

\footnotetext{
${ }^{13}$ I leave it open in this paper whether -mo 'even' scopes out of negation or not (see, for example, the references cited above).

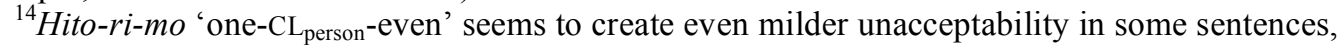
at least to my ears. This minimizer NPI may behave more like dare-mo 'who-MO'.

(i) Hito-ri-mo nani-mo iwa-nakat-ta.

one- $\mathrm{CL}_{\text {person-even what-MO say-not-PAST }}$

'Not a single person said anything.'
} 
a. Satoshi-wa doko-ni-mo ik-kai-mo ika-nakat-ta.

Satoshi-WA where-to-MO one-time-MO go-not-PAST

'Satoshi didn't go anywhere even once.'

b. ??Satoshi-wa ik-kai-mo doko-ni-mo ikanakatta.

Satoshi-WA one-time-MO where-to-MO go-not-PAST

'Satoshi didn't go anywhere even once.'

a. Yoko-wa dare-ni-mo hito-koto-mo iwa-nakat-ta.

Yoko-wA who-to-MO one-word-MO say-not-PAST

'Yoko didn't say a word to anyone.'

b. ??Yoko-wa hito-koto-mo dare-ni-mo iwa-nakat-ta.

Yoko-wA one-word-MO who-to-MO say-not-PAST

'Yoko didn't say a word to anyone.'

Comparing (29) and (30), we can see that the acceptability contrast between the (a)-examples and the (b)-examples above becomes clearer if we add another indeterminate NPI in front of the two NPIs.
a. Dare-mo dare-ni-mo hito-koto-mo iwa-nakat-ta.
who-MO who-to-MO one-word-MO say-not-PAST
'Noone said a word to anyone.'
b. ?*Dare-mo hito-koto-mo dare-ni-mo iwa-nakat-ta.
who-MO one-word-MO who-to-MO say-not-PAST
'Noone said a word to anyone.'

The degraded status of the (b)-examples in (27)-(30) is accounted for in the universal analysis of the indeterminate NPIs because there is a conflicting requirement on scope: the minimizer NPI wants to be in the scope of negation, whereas the indeterminate NPI wants to be outside the scope of negation. ${ }^{15}$ No such conflict arises in the (a)-examples because negation can be between the two types of NPIs. ${ }^{16}$

In contrast, if the minimizers and the indeterminate NPIs were both existentials, it would not be expected that different word orders give rise to any acceptability contrast. One might say that the degraded acceptability of the (b)-

\footnotetext{
${ }^{15}$ The following example forms a minimal pair with example (29b) in that the indeterminate NPI in the latter has been replaced by non-NPI $d a$ 're-ni-mo 'to everyone', which can only take scope above negation. All things being equal, one would expect the acceptability of these two sentences to be more or less the same. At this point I do not have a good explanation as to why the unacceptability of (29b) is much milder than that of (i).

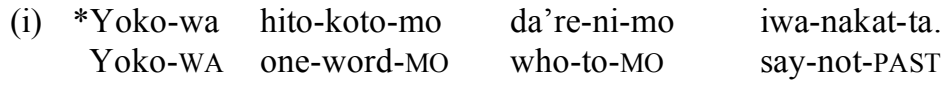

'To everyone, Yoko didn't say a word.'

${ }^{16} \mathrm{~A}$ minimizer scoping over any seems to be not perfect in the double object construction in (iib). If this was generally the case, its implications need to be examined.

(i) a. John didn't offer anything to a single guest.

b. John didn't offer a single drop of wine to anyone.

(ii) a. John didn't offer any guest a single drop of wine.

b. ??John didn't offer a single guest any wine.
} 
examples has to do with the fact that the minimizer NPIs intervene between negation and the indeterminate NPIs, incurring violation of the immediate scope constraint. This explanation, however, does not go through because the (a)examples (as wells as examples in (31) below) show that the immediate scope constraint is not respected when the intervener is also an NPI, even though in general, minimizer NPIs are subject to the constraint, as shown in (32).
a. Dare-mo nani-mo kobos-anakat-ta.
who-MO what-MO spill-not-PAST
'Noone spilled anything.'
b. Hito-ri-mo it-teki-mo kobos-anakat-ta.
one- $\mathrm{CL}_{\text {person-even }}$ one- $\mathrm{CL}_{\mathrm{drop}}$-even spill-not-PAST

'Not a single person spilled a single drop.'
a. Zen'in-ga
it-teki-mo
kobosa-nakat-ta.
all $>\neg>$ one
all-NOM
one- $\mathrm{CL}_{\mathrm{drop}}$-even
spill-not-PAST
'All of them didn't even spill a single drop.'
b. *Zen'in-wa it-teki-mo kobosa-nakat-ta.
all-WA one-CL $\mathrm{drop}_{\text {-even }}$ spill-not-PAST
'Not all of them spilled a single drop.'

Although it is difficult to prove independently that the (b)-examples in (27)-(30) do not involve violation of the immediate scope constraint, it can reasonably be concluded that the data receive a much simpler explanation in the universal analysis of the indeterminate NPIs than in the existential analysis.

\subsection{Indeterminate NPIs and Conjunction}

Let us now examine the configuration in $(25 \mathrm{~b})$, repeated below.

$$
\text { ind-NPI } \quad \mathrm{XP}_{\text {wide }} \quad \neg
$$

The existential analysis predicts that the reading derived from configuration (25b) is not possible because ind-NPI cannot be under negation. The universal analysis, in contrast, predicts that the reading is fine (or that it is not possible if $\mathrm{XP}_{\text {wide }}$ counts as an intervener for the purpose of the immediate scope constraint).

As a phrase that needs to take wide scope over negation $\left(\mathrm{XP}_{\text {wide }}\right)$, a conjunction phrase in the form of ...mo ... mo will be used. As shown in (34), ...mo ...mo conjunctive phrases must take wide scope over negation generally. ${ }^{17}$

\footnotetext{
${ }^{17}$ Though I simply assume here that the ...mo...mo phrase expresses conjunction interpreted over negation (Goro 2007), other possibilities need to be carefully considered. If the ...mo...mo conjunctive phrases turn out to be better viewed as plurals (Szabolcsi and Haddican 2004) or alternative triggering expressions (Shimoyama 2006), ...mo...mo itself does not determine its relative scope with respect to negation. The lack of collective and cumulative readings with the ...mo...mo conjunctive phrases suggests that they are not simple plurals (see also Yamashina and Tancredi 2005).
} 
Takashi-wa [tyuukan-siken-ni-mo kimatu-siken-ni-mo]

Takashi-WA midterm-exam-DAT-MO term.end-exam-DAT-MO

ukat-ta.

pass-PAST

'Takashi passed both the midterm exam and the final exam.'

Takashi-wa [tyuukan-siken-ni-mo kimatu-siken-ni-mo]
Takashi-WA midterm-exam-DAT-MO term.end-exam-DAT-MO
ukara-nakat-ta.
pass-not-PAST
'Takashi didn't pass the midterm exam or the final exam.'

Sentence (35) below is fine in the reading shown, as expected in the universal analysis of dare-mo 'who-MO'.
Dare-mo [tyuukan-siken-ni-mo
kimatu-siken-ni-mo]
who-MO midterm-exam-DAT-MO
term.end-exam-DAT-MO
ukara-nakat-ta.
pass-not-PAST
'No one passed the midterm exam or the final exam.' $(\forall \& \neg)$

Note that the reading in question could also be derived from LFs where the conjunctive phrase c-commands the NPI dare-mo 'who-MO' ( $\& \forall \neg ; \& \neg \exists$ ). One might say, then, that (35) does not add support to the universal analysis since it can be handled in the existential analysis as well. However, sentences where an inverse scope reading of two arguments is possible typically involve scrambling, which (35) does not. Also, the relevant reading is easily available even when we have an intonational pause between the subject and the object to make the inverse scope reading less accessible. We thus conclude that dare-mo and the conjunctive phrase are interpreted without changing their surface scope relation, and maintain that (35) provides additional support for the universal analysis. ${ }^{18}$

\footnotetext{
${ }^{18}$ Disjunction in Japanese also has to scope over negation, as shown in (i) (see Goro 2007 for discussions and references). Here, matawa 'or' is used instead of more frequently discussed $k a$ 'or' because the latter does not combine well with indeterminate NPIs.

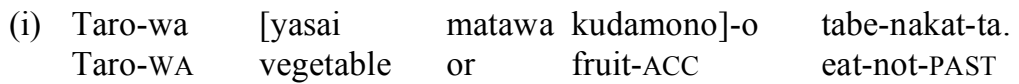

'Taro didn't eat vegetables, or didn't eat fruits.'

It is possible to disjoin two indeterminate NPIs as in (ii), which may suggest that these NPIs are wide scope universals (thanks to Andrea Gualmini for suggesting to look at this type of sentences). However, I leave verification of this point for future because the source of the widescope-like reading of disjunction needs to be carefully examined. It is possible that this type of sentence involves disjunction of larger constituents including negation at LF, or that it receives a Hamblin style analysis (e.g., Alonso-Ovalle 2006).
(ii) Taro-wa
[yasai-o nani-mo matawa
Taro-WA vegetable-ACC what-MO or
'Taro ate no vegetables, or ate no fruits.'
kudamono-o nami-mo] tabe-nakat-ta.
fruit-ACC what-MO
eat-not-PAST




\section{A Note on Exceptive -sika NPIs}

I will now briefly touch upon another type of NPI in Japanese, which has an exceptive semantics. Like indeterminate NPIs, -sika NPIs require clausemate sentential negation, as in (36). These sentences become ungrammatical when the negation is removed.

a. Taro-sika gakusei-ga odora-nakat-ta.

Taro-SIKA student-NOM dance-not-PAST

'No student but Taro danced.'

$=$ 'Every student but Taro didn't dance.'

b. Bill-wa Taro-sika gakusei-o syootaisi-nakat-ta.

Bill-wA Taro-SIKA student-ACC invite-not-PAST

'Bill didn't invite any student but Taro.'

$=$ 'Every student but Taro is such that Bill didn't invite him or her.'

As far as simple sentences like (36) are concerned, the -sika NPIs could be narrow scope existential or wide scope universal, a situation similar to indeterminate NPIs. Following roughly a version of von Fintel's (1993) semantics for exceptive but phrases, we can describe the meaning of, for example, sentence (36a), either with existential under negation (37a) or with universal over negation (37b) (see also Gajewski 2008).

a. $\neg \exists x[(\operatorname{student}-\{\operatorname{tar}\})(\mathrm{x}) \& \operatorname{dance}(\mathrm{x})] \& \neg \neg \exists \mathrm{y}[\operatorname{student}(\mathrm{y}) \&$ dance(y)] $=\neg \exists x[(\operatorname{student}-\{\operatorname{tar}\})(\mathrm{x}) \& \operatorname{dance}(\mathrm{x})] \& \exists \mathrm{y}[\operatorname{student}(\mathrm{y}) \& \operatorname{dance}(\mathrm{y})]$

b. $\forall \mathrm{x}[(\operatorname{student}-\{\operatorname{tar} 0\})(\mathrm{x}) \rightarrow \neg \operatorname{dance}(\mathrm{x})] \& \neg \forall \mathrm{y}[($ student $)(\mathrm{y})$ $\rightarrow \neg$ dance $(\mathrm{y})]$ $=\forall \mathrm{x}[(\operatorname{student}-\{\operatorname{taro}\})(\mathrm{x}) \rightarrow \neg \operatorname{dance}(\mathrm{x})] \& \exists \mathrm{y}[\operatorname{student}(\mathrm{y}) \& \operatorname{dance}(\mathrm{y})]$

In either analysis, it follows that Taro is a student, no student who is not Taro danced, and Taro danced.

When we look at examples where -sika NPIs cooccur with indeterminate NPIs as in the next two examples, we can see that if indeterminate NPIs are universals, -sika NPIs must be, too.

Kaori-sika doko-ni-mo ika-nakat-ta.

Kaori-SIKA where-to-MO go-not-Past

'Only Kaori went somewhere.'

(39) Doko-ni-mo Kaori-sika ika-nakat-ta.

where-to-MO Kaori-SIKA go-not-Past

'Every place is such that only Kaori went there.' 
The meanings of sentences (38) and (39) can be described in (40) and (41), respectively. ${ }^{19,20}$ If we assume that both the indeterminate NPI and the -sika NPI were existentials, we get (40a) and (41a). Or if we assume that both the indeterminate NPI and the -sika NPI were universals, we get (40b) and (41b). Either way, we arrive at the same meaning, as paraphrased in (40c) and (41c). ${ }^{21}$

a. $\neg \exists \mathrm{x}, \mathrm{y}[($ person- $\{\operatorname{kaori}\})(\mathrm{x}) \&$ place $(\mathrm{y}) \&$ went to $(\mathrm{x}, \mathrm{y})] \&$ $\exists \mathrm{x}, \mathrm{y}[$ person(x) \& place(y) \& went to $(\mathrm{x}, \mathrm{y})]$

b. $\forall \mathrm{x}, \mathrm{y}[($ person- $\{$ kaori $\})(\mathrm{x}) \& \operatorname{place}(\mathrm{y}) \rightarrow \neg$ went to $(\mathrm{x}, \mathrm{y})] \&$ $\neg \forall \mathrm{x}, \mathrm{y}[$ person $(\mathrm{x}) \&$ place $(\mathrm{y}) \rightarrow \neg$ went to $(\mathrm{x}, \mathrm{y})]$

$=\forall \mathrm{x}, \mathrm{y}[($ person $-\{$ kaori $\})(\mathrm{x}) \& \operatorname{place}(\mathrm{y}) \rightarrow \neg$ went to $(\mathrm{x}, \mathrm{y})] \&$ $\exists \mathrm{x}, \mathrm{y}[$ person(x) \& place $(\mathrm{y}) \&$ went to $(\mathrm{x}, \mathrm{y})]$

c. 'Everyone who is not Kaori went nowhere, and there is someone who went somewhere (i.e., Kaori).'

a. $\neg \exists y[$ place $(y) \&[\exists x[($ person- $\{$ kaori $\})(x) \&$ went to $(x, y)] \&$ $\neg \exists \mathrm{z}[\operatorname{person}(\mathrm{z}) \&$ went to $(\mathrm{z}, \mathrm{y})]]]$

$=\neg \exists \mathrm{x}, \mathrm{y}[$ place $(\mathrm{y}) \&($ person- $\{$ kaori $\})(\mathrm{x}) \&$ went to $(\mathrm{x}, \mathrm{y}) \&$ $\neg \exists \mathrm{z}[\operatorname{person}(\mathrm{z}) \&$ went to $(\mathrm{z}, \mathrm{y})]]$

b. $\forall y[$ place $(y) \rightarrow[\forall x[($ person- $\{$ kaori $\})(\mathrm{x}) \rightarrow \neg$ went to $(\mathrm{x}, \mathrm{y})] \&$ $\neg \forall \mathrm{z}[\operatorname{person}(\mathrm{z}) \rightarrow \neg$ went to $(\mathrm{z}, \mathrm{y})]]]$

$=\forall \mathrm{x}, \mathrm{y}[$ place $(\mathrm{y}) \&($ person $-\{$ kaori $\})(\mathrm{x}) \rightarrow \neg$ went to $(\mathrm{x}, \mathrm{y}) \& \exists \mathrm{z}[\operatorname{person}(\mathrm{z})$ \& went to $(\mathrm{z}, \mathrm{y})]]$

${ }^{19}$ In (39), the reading of (38) may be available for some speakers presumably due to the availability of a reconstruction site for doko-ni-mo 'where-to-MO'. Alternatively, it has to do with the fact that (38) is true in all situations where (39) is true.

${ }^{20}$ Here are Korean examples of a similar type from Sells (2001). It is reported there that most speakers consulted accepted these sentences with the readings indicated.

(i) Swuni-pakkey amwu kes-to mek-ci anh-ass-ta.

Swuni-PAKKEY anything eat-COMP NEG-PAST-DECL

'Except for Swuni, no one ate anything (only Swuni ate something).'

(ii) Amwu-to i kes-pakkey ilk-ci anh-ass-ta.

anyone this thing-PAKKEY read-COMP NEG-PAST-DECL

'Everyone read only this.'

${ }^{21}$ It is proposed in Kataoka (2006a,b) that -sika NPIs and indeterminate NPIs must c-command negation based on data from scrambling. -Sika NPIs, in particular, are proposed to occupy Spec of NegP to account for the fact that quantificational phrases do not occur between -sika NPI and negation at LF (the assumption there seems to be that there are no multiple specifiers or adjunction to Neg'). Indeterminate NPIs, then, could only occur above -sika NPIs, and examples like (38) and their Korean counterparts would be excluded as ungrammatical. Given that indeterminate NPIs are also subject to the generalized immediate scope constraint, and the constraint is sometimes not obeyed, the -sika NPI facts should be viewed as an effect of the generalized immediate scope constraint, as we have been assuming in this paper, rather than as a result of strict unavailability of syntactic positions between -sika NPI and negation. 
c. 'Everyone who is not Kaori went nowhere, and every place was visited by someone (i.e., Kaori).'

Suppose now instead that indeterminate NPIs are universals and -sika NPIs are existentials. That should work for sentences like (39), but not for sentences like (38). In (38), if doko-ni-mo 'where-to-MO' is outside the scope of negation, Kaori-sika cannot be inside negation. Even if covert scope shifting was possible, that would give us the wrong meaning. In a similar manner, it cannot be the case that indeterminate NPIs are existentials while -sika NPIs are universals. This assumption is problematic for (39), as it is not possible that Kaori-sika is above negation and doko-ni-mo 'where-to-MO' is below negation at the same time. Again, if scope shifted covertly, only the other reading would be derived. The conclusion we reach here is that, if we are on the right track about indeterminate NPIs being interpreted as universals, then a sentence like (38) is evidence that sika NPIs should also be universals. Details aside, the lexical meaning of -sika will be roughly like (42), using von Fintel's (1993) semantics. ${ }^{22}$

$$
[[-\mathrm{sika}]]=\lambda \mathrm{E}_{<\mathrm{et}>} \lambda \mathrm{R}_{<\mathrm{et}>} \lambda \mathrm{P}_{<\mathrm{et}>}[\forall(\mathrm{R}-\mathrm{E})(\mathrm{P}) \& \neg \forall(\mathrm{R})(\mathrm{P})]
$$

\section{Conclusion}

I showed that there are contexts where indeterminate NPIs must be interpreted as wide scope universals but not as narrow scope existentials, and presented further supporting evidence for the universal analysis. I hope to have shown that the idea is at least worth pursuing further. One of the many issues that are not addressed in this paper is whether indeterminate NPIs could tell us whether there are good reasons to believe that indeterminate pronouns denote sets of alternatives in general (Shimoyama 2006). If it turns out that indeterminate NPIs generally allow non-local association between indeterminates and -mo (see Kuroda 2005), adopting the alternative semantic analysis would make a simpler syntax-semantics mapping possible. ${ }^{23}$

\footnotetext{
${ }^{22}$ Like indeterminate NPIs, -sika NPIs need to be specified to require local sentential negation. Also, the lexical semantics of -sika has to be generalized to accommodate the cross-categorial nature of -sika. I must leave for future the question of whether -sika NPI is better analyzed as an alternative triggering expression (Alonso-Ovalle and Hirotani 2004).

${ }^{23}$ Interactions between indeterminate NPIs and modals requires investigation. On the one hand, the availability of the de re reading in (i) seems to require a universal interpretation of daremo: $\forall$ POSSIBLE $\neg$. On the other hand, the availability of the de dicto reading in (ii) seems to indicate that dare-mo here is interpreted existentially: $\neg$ POSSIBLE $\exists$.

(i) Gakusei-o dare-mo kaikosi-naku-te ii. POS $\neg$ (or $\neg$ NEC) student-ACC who-MO fire-not-TE good

'(We're) allowed not to fire any student.'

a. 'For every student, we are allowed not to fire him or her.' (de re)

b. 'It is allowed that we fire no students.' (de dicto)

(ii) Saburo-wa seizika-o dare-mo yonde-wa ikenai. $\neg$ POS (or NEC $\neg$ )

Saburo-TOP politician-ACC who-MO invite-WA go.not

'Saburo is not allowed to invite any politician.'
} 


\section{References}

Alonso-Ovalle, Luis: 2006, Disjunction in Alternative Semantics. Doctoral Dissertation, University of Massachusetts at Amherst.

Alonso-Ovalle, Luis and Masako Hirotani: 2004, 'A Negative Concord Exceptive: Japanese -sika', Poster presented at NELS 35, University of Connecticut.

Carlson, Gregory: 1980, 'Polarity Any is Existential', Linguistic Inquiry 11, 799804.

Chierchia, Gennaro: 2004, 'Scalar Implicatures, Polarity Phenomena and the Syntax/Pragmatics Interface', in A. Belletti (ed.) Structures and Beyond, 39-103, Oxford University Press.

von Fintel, Kai. 1993. Exceptive constructions, Natural Language Semantics 1, 123-148.

Gajewski, Jon: 2008, 'NPI any and Connected Exceptive Phrases', Natural Language Semantics 16, 69-110.

Giannakidou, Anastasia: 2000, 'Negative ... Concord?', Natural Language and Linguistic Theory 18, 457-523.

Goro, Takuya: 2007, Language-Specific Constraints on Scope Interpretation in First Language Acquisition. Doctoral Dissertation, University of Maryland, College Park.

Guerzoni, Elena: 2006, 'Intervention Effects on NPIs and Feature Movement: Towards a Unified Account of Intervention', Natural Language Semantics 14, 359-398.

Hagstrom, Paul: 1997, '-Mo as Universal Quantification over Choice Functions', Ms. MIT.

Han, Chung-hye, Jeffrey Lidz and Julien Musolino: 2007, 'Verb-raising and Grammar Competition in Korean: Evidence from Negation and Quantifier Scope', Linguistic Inquiry 38, 1-47.

Kadmon, Nirit and Fred Landman: 1993, 'Any', Linguistics and Philosophy 16, 353-422.

Kataoka, Kiyoko: 2006a, Nihongo hiteibun-no koozoo: Kakimazebun-to hiteikooo-hyoogen (Syntactic structure of Japanese negative sentences: Scrambling construction and negation-sensitive elements). Kurosio, Tokyo.

Kataoka, Kiyoko: 2006b, 'Neg-sensitive Elements, Neg-c-command, and Scrambling in Japanese', in T. J. Vance and K. Jones (eds.) Japanese/Korean Linguistics Vol. 14, CSLI Publications, 221-233.

Kato, Yasuhiko: 1985, Negative Sentences in Japanese. Sophia Linguistica Monograph 19. Sophia University, Tokyo.

a. 'For no politician, Saburo is allowed to invite him or her.' (de re)

b. 'It is not allowed that Saburo invites a politician.' (de dicto)

If the modal in (ii) was a necessity modal, the de dicto reading can be captured by the universal analysis. A similar reanalysis of (i), however, would necessitate an existential interpretation of dare-mo in the de dicto context. More data should be examined, and both synchronic and diachronic properties of certain modal expressions need to be investigated. 
Kawashima, Ruriko: 1994, The Structure of Noun Phrases and the Interpretation of Quantificational NPs in Japanese. Doctoral dissertation, Cornell University.

Kim, Shin-Sook and Peter Sells: 2007, 'Generalizing the Immediate Scope Constraint on NPI Licensing', in H. Zeijlstra and J.-P. Soehn (eds.) Proceedings of the Workshop on Negation and Polarity, Collaborative Research Center 441, University of Tübingen, 85-91.

Kuroda, S.-Y.: 2005, 'Prosody and the Syntax of Indeterminates', in D. Roehrs, O.-H. Kim and Y. Kitagawa (eds.) Indiana University Working Papers in Linguistics, vol. 5: Syntax and Beyond.

Ladusaw, William: 1979. Polarity Sensitivity as Inherent Scope Relations. Doctoral Dissertation, University of Texas, Austin.

Lahiri, Utpal: 1998, 'Focus and Negative Polarity in Hindi', Natural Language Semantics 6, 57-123.

Linebarger, Marcia: 1987, 'Negative Polarity and Grammatical Representation', Linguistics and Philosophy 10, 325-387.

Nakanishi, Kimiko: 2006, 'Even, Only and Negative Polarity in Japanese', in M. Gibson and J. Howell (eds.) Proceedings of SALT XVI, 138-155, CLC Publications, Cornell University, Ithaca.

Nam, Seungho: 1994, 'Another Type of Negative Polarity Item', in M. Kanazawa and C. Piñon (eds.) Dynamic Polarity and Quantification, 3-15, CSLI, Stanford.

Sells, Peter: 2001, 'Negative Polarity Licensing and Interpretation', in S. Kuno et al. (eds.) Harvard Studies in Korean Linguistics 9.

Sells, Peter: 2006, 'Interactions of Negative Polarity Items in Korean', in S. Kuno et al. (eds.) Harvard Studies in Korean Linguistics 11, 724-737.

Shimoyama, Junko: 2004, 'Wide Scope Universal NPIs in Japanese', handout for Georgetown University Round Table on Languages and Linguistics (GURT 2004): Comparative and Cross-Linguistic Research in Syntax, Semantics, and Computational Linguistics.

Shimoyama, Junko: 2006, 'Indeterminate Phrase Quantification in Japanese', Natural Language Semantics 14, 139-173.

Szabolcsi, Anna: 1981, 'The Semantics of Topic-Focus Articulation', in J. Groenendijk, T. Janssen and M. Stokhof (eds.) Formal Methods in the Study of Language, Mathematical Centre Tracts 136, Amsterdam, 513-540.

Szabolcsi, Anna and Bill Haddican: 2004, 'Conjunction Meets Negation: A Study in Cross-linguistic Variation', Journal of Semantics 21, 219-249.

Watanabe, Akira: 2004, 'The Genesis of Negative Concord: Syntax and Morphology of Negative Doubling', Linguistic Inquiry 35, 559-612.

Yamashina, Miyuki and Christopher Tancredi: 2005, 'Degenerate plurals', in Proceedings of SuB9, 522-537.

Zeijlstra, Hedde: 2004, Sentential Negation and Negative Concord, Doctoral Dissertation, University of Amsterdam.

Zwarts, Frans: 1998, 'Three Types of Polarity', in F. Hamm and E. Hinrichs (eds.) Plurality and Quantification, 177-238, Kluwer, Dordrecht. 